\title{
OIL AND GREASE IN SOILS IRRIGATED WITH GREYWATER AND THE POTENTIAL EFFECT ON SOIL WATER REPELLENCY
}

\author{
Michael Travis \\ Noam Weisbrod \\ Amit Gross \\ Ben-Gurion University of the Negev, Israel
}

\begin{abstract}
The reuse of greywater and other wastewaters are important considerations for effective water management strategies. It is also imperative that the potential for detrimental environmental effects be investigated. As part of ongoing research into the reuse of greywater and oil-rich agro-wastewaters, the potential impact of oil and grease (O\&G) to soils irrigated with greywater $(\mathrm{GW})$ was studied. Greywater streams were sampled and analyzed for $O \& G$ content. Along with the greywater, soil profile samples were collected from garden soils irrigated with these waters. The goal was to determine the $O \& G$ content of these GW streams, verify ifø $\& \mathrm{G}$ was accumulating in the soil profiles, and investigate the effect $O \& G$ can have on water movement through O\&G contaminated soils.

Untreated kitchen GW averaged $200 \mathrm{mg} / \mathrm{L} \mathrm{O \& G}$, over an order of magnitude more than other GW streams. GW-irrigated soils showed O\&G accumulation of up to $200 \mathrm{mg} / \mathrm{kg}$ within the first $20-\mathrm{cm}$ of depth. GW with low $O \& G$ concentration $(<10 \mathrm{mg} / \mathrm{L})$ still demonstrated long-term accumulation in the soil profile, with O\&G concentration of $150 \mathrm{mg} / \mathrm{kg}$. To determine the potential effects that $O \& G$ accumulation may have on water movement in soil, capillary rise and water drop penetration time (WDPT) experiments were conducted. The results showed up to $60 \%$ decrease in capillary rise in sand containing $250 \mathrm{mg} / \mathrm{kg}$ O\&G. Interestingly, no additional reduction in capillary rise was observed at concentrations above $250 \mathrm{mg} / \mathrm{kg}$. WDPT was observed to increase linearly (from nearly instantaneous to over 2 seconds) with increased O\&G content, up to $1000 \mathrm{mg} / \mathrm{kg}$. This work demonstrated that $\mathrm{O} \& \mathrm{G}$ in $\mathrm{GW}$ used for irrigation can accumulate in soil and may lead to a significant water repellency and reduction in the soils ability to transmit water.
\end{abstract}

\section{KEYWORDS}

Oil; Grease; Greywater; Hydrophobicity; Water Repellency; Capillary Rise.

\section{INTRODUCTION}

In recent years the reuse of $\mathrm{GW}$ for irrigation has taken on increasing interest as a means of water conservation. Greywater is generally defined as household wastewater excluding toilet effluent. It is a frequent misconception that $\mathrm{GW}$ is cleaner than combined domestic wastewater and therefore can be reused with minimal or no treatment [1]. Significant components of GW include biochemical oxygen demand 
(BOD), chemical oxygen demand (COD), total suspended solids (TSS), ammonium $\left(\mathrm{NH}_{4}{ }^{+}\right)$, total phosphorus (TP), fecal coliform (FC), surfactants and O\&G [2]. Untreated domestic wastewater typically contains 50 to $100 \mathrm{mg} / \mathrm{L} \mathrm{O \& G} \mathrm{[3],} \mathrm{with} \mathrm{approximately}$ $2 / 3$ of the load contributed by greywater [4]. Over $90 \%$ of the domestic O\&G load is removed through typical sewage treatment systems, however, when GW is reused without adequate treatment $O \& G$ is a potentially significant component. Research on the potential environmental impact of $O \& G$ from $G W$ has been absent from the literature. Kitchen GW is reported as the highest contributor of $O \& G$ in domestic GW, but $O \& G$ is present in all GW streams [2]. Oil and grease is non-polar and therefore hydrophobic, a condition classically defined by a contact angle at the interface with water of greater than $90^{\circ}$. When present in soils, O\&G may affect the contact angle of soil minerals with water. Soils that exhibit contact angles greater than $90^{\circ}$ prevent water infiltration. When contact angles are greater than $0^{\circ}$ but less than $90^{\circ}$, soils exhibit varying degrees of water repellency and reduced water movement $[5,6]$. The presence of organic coatings on soil particles or of hydrophobic compounds within the soil matrix is generally considered the major cause of soil water repellency [7]. Soil water repellency can lead to runoff, ponding, or preferential flow that results in more rapid downward transport of contaminants [8]. Common methods to identify water repellency in soils are the water droplet penetration time (WDPT) test, and the capillary rise method. The objectives of this study were to characterize GW for the presence of $O \& G$, investigate $O \& G$ accumulation in soil as a result of $G W$ irrigation, and study its potential contribution to soil water repellency.

\section{METHODS}

\subsection{Greywater and soil sampling}

Six GW streams from sites in the in the central Negev Desert, Israel were sampled between July 3 and September 18, 2005. The six streams represented various household GW combinations, and included: ( 1 and 2 ) untreated bath; (3) treated bath and laundry; (4) treated bath, laundry and kitchen; (5) untreated kitchen; and (6) treated kitchen. Greywater stream 3 was treated with a recycled vertical flow constructed wetland (RVFCW) [1], and GW stream 4 was treated using a commercially available aerobic system. The treatment for kitchen GW (stream 6) consisted of an anaerobic tank with estimated three-day retention. All six streams were used for ornamental garden irrigation. Samples were analyzed for the following parameters in accordance with procedures outlined in Standard Methods [9]: TSS; $\mathrm{NH}_{4}{ }^{+}$; total nitrogen (TN); TP; anionic surfactants; COD; and BOD. Oil and grease was analyzed by solid phase extraction (SPE) using EPA Method 1664A [10].

Soil cores were collected from the irrigated garden plots at $5-\mathrm{cm}$ intervals to $20-\mathrm{cm}$, then at $20-\mathrm{cm}$ intervals to $60-\mathrm{cm}$. The GW had been applied directly to the soil surface with no apparent mechanical mixing or tillage of the soil. Background samples were collected of similar soils that had not received GW. After collection, soil samples were dried at $65^{\circ} \mathrm{C}$ and extracted for gravimetric O\&G measurement by accelerated solvent extraction (ASEế) methodology using hexane.

\subsection{Water repellency}


To assess potential development of water repellency in O\&G-contaminated soil, two methods were used: water droplet penetration time (WDPT) and capillary rise. Since sand is commonly used in gardens in the Negev, clean, uniform quarry silica sand (average diameter: $110 \mu \mathrm{m}$; uniformity coefficient: 1.9) was used to provide consistency and repeatability of the tests. The method for WDPT consisted of placing droplets of water on the soil surface and timing imbibition [6]. At least three measurements were made for each soil, and average time of droplet penetration calculated.

Capillary rise procedures were similar to those described by Wiel-Shafran et al. [11]. The sand was prepared by thoroughly mixing with artificial GW composed of fresh water, shampoo, laundry powder and sunflower oil to $10 \%$ gravimetric moisture content (MC). Artificial GW was used instead of actual GW to assure uniformity and repeatability. The amount of vegetable oil was varied to produce concentrations of 0 , $50,100,250,500$ and $1000 \mathrm{mg} / \mathrm{kg}$ O\&G in the moist sand. The O\&G was emulsified into the artificial GW samples with a high shear mixer, and then the solution mixed into the sand. The prepared soils were stored at $4{ }^{\circ} \mathrm{C}$ to minimize potential biological degradation prior to use. Soil columns were prepared in triplicate for each O\&G concentration. An additional batch was later prepared with $200 \mathrm{mg} / \mathrm{kg}$ O\&G for tests observing the effect of storage time since $O \& G$ addition on imbibition. Each column was uniformly packed and a \#200 mesh screen secured over the bottom of the column. The columns were weighed as a means of checking consistency of packing. Dry bulk densities of the prepared columns were calculated to be $1.49 \pm 0.02 \mathrm{~g} / \mathrm{cm}^{3}$. To perform each capillary rise test, the soil column was clamped vertically to a stand and placed on a laboratory balance. A scissors jack placed upon a "bridge" over the balance supported the fresh water imbibing solution in a manner to not interfere with measurement of the soil column mass. The balance was tared to zero and the imbibing solution carefully raised until contact was made with the soil column. Once contact was made imbibition quickly proceeded and the change in column mass was recorded via direct output to data logging software.

Capillary movement of liquid into porous media is described for static (equilibrium) conditions by the following equation [12]:

$H=\frac{2 \gamma_{\iota} \cos \theta_{\iota 4}}{r \rho g}$

where $H$ is the maximum height of liquid imbibition into a soil column; $\gamma_{L}$ is the liquid surface tension; $\theta_{e q}$ is the solid/liquid contact angle at equilibrium; $r$ is the effective pore radius; $\rho$ is the imbibing liquid density; and $g$ is the acceleration due to gravity. During active (dynamic) capillary movement into porous media, imbibition is described according to Washburn's equation [13]:

$\mathrm{w}^{2}=c \frac{\gamma_{L} \cos \theta_{d y}}{2 \eta} t$

where $w$ is the mass of water imbibed at time $t ; c$ is a geometric factor encompassing capillary radius, soil porosity, and the soil column cross-sectional area; $\theta_{d v}$ is the solid/liquid contact angle during active imbibition; and $\eta$ is the viscosity of the liquid. Dynamic contact angle is related to the speed of capillary rise [14] and gravitational 
effects [15]. Under experimental conditions where the liquid properties are known, both equations have two unknown parameters: namely $\theta_{e q}$ and $r$, or $\theta_{d v}$ and $c$ (Equation $l$ or Equation 2, respectively). By conducting preliminary tests with a perfect liquid, i.e., an imbibing liquid that has a contact angle of zero [14], each equation is reduced to one unknown, $r$ or $c$. These parameters were calculated based on experimentally determined $H$ and $\frac{w^{2}}{t}$ using ethanol as the imbibing liquid. Once parameters $r$ and $c$ were determined, they were used to calculate $\theta$ for subsequent capillary rise tests using fresh water as the imbibing liquid. Since $H$ could not be visually observed in the moist sand column, it was calculated from the total weight of liquid imbibed, $W$, according to the relationship between $H$ and $W$ in porous media:

$$
W=H n \rho \pi R^{2}
$$

where $n$ is porosity of the sand, and $R$ is the radius of the column.

\section{RESULTS AND DISCUSSION}

\subsection{Greywater quality}

Greywater quality results are summarized in Table 1. Data from the two untreated bathroom streams were combined into one set. The $\mathrm{pH}$ and $\mathrm{EC}$ of all streams were typical of $\mathrm{GW}$, ranging from 5.7 to 7.6 and 1.1 to $1.6 \mathrm{mS} / \mathrm{cm}$, respectively. $\mathrm{pH}$ was highest in streams containing laundry GW. This may be attributed to the high alkalinity of typical laundry detergents [16]. Organic load (i.e., BOD, COD) was highest in kitchen GW (either treated or untreated). This agrees with findings of Friedler [2] who observed kitchen GW to comprise $26 \%$ of the total GW volume and yet contribute over $40 \%$ of the TSS, COD, BOD and O\&G. This notably high waste strength of kitchen

Table 1. Average \pm standard error concentrations of greywater quality parameters from household streams located in Midreshet Ben-Gurion, Israel. Results are based on 14 samples for the bath $G W$ and 7 for the other streams. All concentrations are in $m g L^{-1}$ unless stated otherwise.

\begin{tabular}{ccccccccccc}
\hline Parameter & $\begin{array}{c}\text { Bath } \\
\text { untreated }\end{array}$ & $\begin{array}{c}\text { Kitchen } \\
\text { untreated }\end{array}$ & $\begin{array}{c}\text { Kitchen } \\
\text { treated }\end{array}$ & $\begin{array}{c}\text { Kitchen, } \\
\text { bath, laundry } \\
\text { treated }\end{array}$ & $\begin{array}{c}\text { Bath } \\
\text { Laundry } \\
\text { treated }\end{array}$ \\
\hline $\mathrm{pH}$ & 7.3 & \pm 0.1 & 5.7 & \pm 0.3 & 7.1 & \pm 0.2 & 7.4 & \pm 0.1 & 7.6 & \pm 0.1 \\
\hline Electrical conductivity $(\mathrm{mS} / \mathrm{cm})$ & 1.13 & \pm 0.05 & 1.22 & \pm 0.12 & 1.65 & \pm 0.10 & 1.20 & \pm 0.06 & 1.43 & \pm 0.08 \\
\hline Total suspended solids & 153 & \pm 83 & 1250 & \pm 860 & 983 & \pm 850 & 19 & \pm 4 & 17 & \pm 5 \\
\hline Ammonium nitrogen & 0.65 & \pm 0.2 & 0.99 & \pm 0.6 & 2.18 & \pm 1.4 & 1.26 & \pm 0.8 & 1.42 & \pm 0.8 \\
\hline Total nitrogen & 7.2 & \pm 1.8 & 22 & \pm 7.0 & 30 & \pm 10 & 6.3 & \pm 0.4 & 7.5 & \pm 1.1 \\
\hline Total phosphorus & 2.8 & \pm 1.3 & 3.7 & \pm 0.8 & 12.3 & \pm 9.6 & 2.9 & \pm 0.4 & 7.6 & \pm 2.3 \\
\hline Anionic surfactants & 4.1 & \pm 0.6 & 8.2 & \pm 1.0 & 14.1 & \pm 1.8 & 0.4 & \pm 0.1 & 1.8 & \pm 0.9 \\
\hline Chemical oxygen demand & 435 & \pm 130 & 2180 & \pm 690 & 2200 & \pm 1090 & 99 & \pm 20 & 123 & \pm 51 \\
\hline Biochemical oxygen demand & 44 & \pm 5 & 1042 & \pm 320 & 172 & \pm 67 & 9 & \pm 2 & 8 & \pm 5 \\
\hline Oil \& grease & 7.2 & \pm 1.1 & 195 & \pm 67 & 45.3 & \pm 36.3 & 4.3 & \pm 2.7 & 5.3 & \pm 2.3 \\
\hline
\end{tabular}


GW leads to the practice of some researchers to exclude it from the definition of GW. Oil and grease content of untreated kitchen GW averaged $195 \mathrm{mg} / \mathrm{L}$, more than an order of magnitude higher than other GW sources, and more than double typical concentrations found in raw domestic wastewater [3]. All other GW streams usually

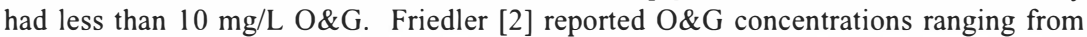
$77 \mathrm{mg} / \mathrm{L}$ for bath to $323 \mathrm{mg} / \mathrm{L}$ for kitchen $\mathrm{GW}$. The lower O\&G concentrations reported in this work may be the result of differences in extraction method, or the result of high variation between different streams.

\subsection{O\&G in GW-irrigated soil}

Concentrations of $\mathrm{O} \& \mathrm{G}$ in the background soil (not irrigated with $\mathrm{GW}$ ) were consistently less than $50 \mathrm{mg} / \mathrm{kg}$ (Figure la). Soils that had been irrigated with GW for two years or less had similar concentrations, with no measured O\&G accumulation (not shown). It has been reported in the literature that lipids are readily degraded in soils and that accumulation of O\&G is not expected [17]. The published research, however, has typically only observed the fate of single O\&G applications, whereas GW irrigation systems represent ongoing O\&G addition to the soil. Two of our research sites were subject to surface irrigation by GW for more than seven years. The soil profiles at these sites showed O\&G accumulation in the upper $20 \mathrm{~cm}$ of $150 \mathrm{mg} / \mathrm{kg}$ for bath $\mathrm{GW}$ irrigated soil (Figure 1 b) and $200 \mathrm{mg} / \mathrm{kg}$ for kitchen GW-irrigated soil (Figure 1c). In both profiles $O \& G$ concentrations were $<50 \mathrm{mg} / \mathrm{kg}$ below a depth of $20 \mathrm{~cm}$. It should be noted that despite an order of magnitude difference in $O \& G$ concentration in the GW, maximum concentrations in the kitchen-irrigated soil were only about $30 \%$ higher than the bath-irrigated soil. This may be because of vertical migration of the $\mathrm{O} \& \mathrm{G}$, as noted by the greater depth of $O \& G$ in the kitchen-irrigated soil profile compared to the bathirrigated soil. However, O\&G concentrations did not exceed background levels for either profile below a depth of $20 \mathrm{~cm}$. The data agrees with results reported by Cecutti et al. [18], in which fatty acids with a chain length of more than 16 carbons were not detected below a soil depth of $25 \mathrm{~cm}$.

\subsection{Soil water repellency}

Water droplet penetration time tests conducted on air-dried soil samples from GW irrigated garden soils showed little correlation to measured O\&G concentrations (Figure $2 a$ ). It is suggested that the presence of other compounds in greywater, e.g., surfactants, may also influence hydrophobic characteristics of soil irrigated with GW preventing a direct correlation with $O \& G$ concentrations. Water droplet penetration time tests were also run on each of the prepared oil-containing sands. These soils contained similar concentrations of compounds contributed by the artificial GW, with O\&G the only variable. Penetration times ranged from nearly instantaneous to about 2 seconds (Figure $2 b$ ). The increase in penetration time versus O\&G concentration was linear with an $R^{2}$ value of 0.97 . The data indicate that $O \& G$ accumulation in soil can directly affect water imbibition. 


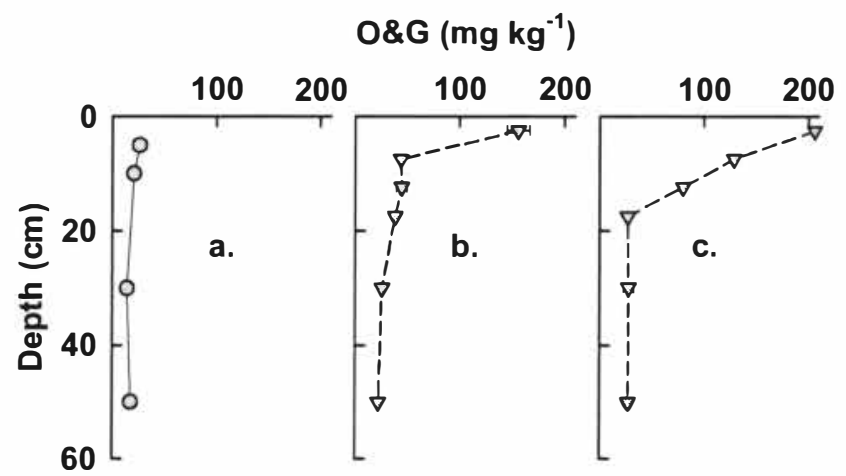

Figure 1. Mean \pm standard error concentrations of oil and grease $(O \& G)$ in garden soil profile Midreshet Ben-Gurion, Israel. Soil irrigated with: a) freshwater; b) bath greywater; c) kitchen greywater; $n=3$. 


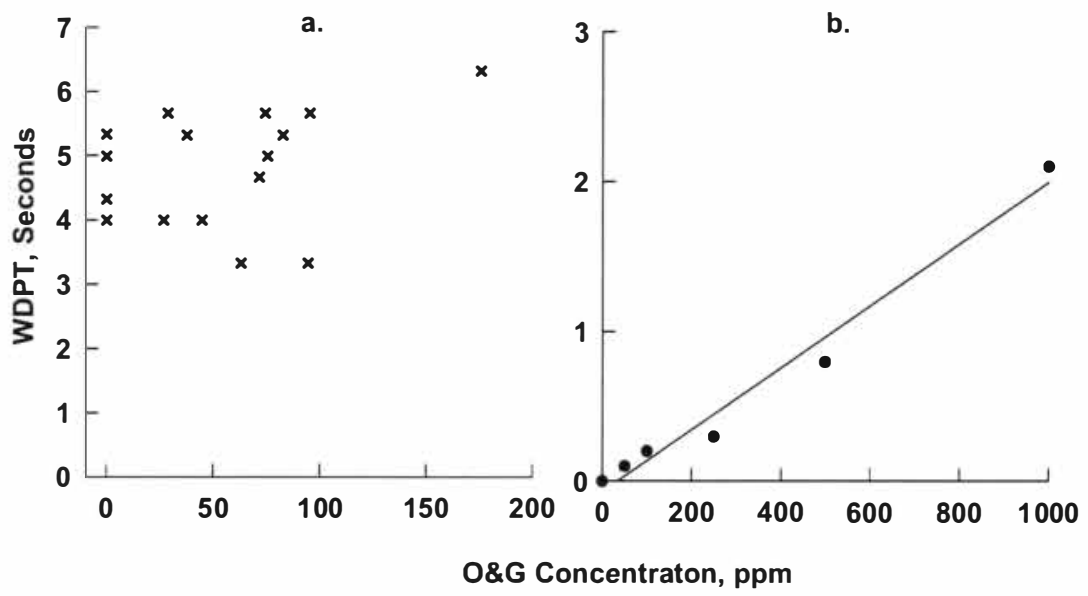

Figure 2. Water droplet penetration time versus $O \& G$ concentration in: a) garden soils irrigated with greywater, and b) laboratory prepared soil with different O\&G concentrations.
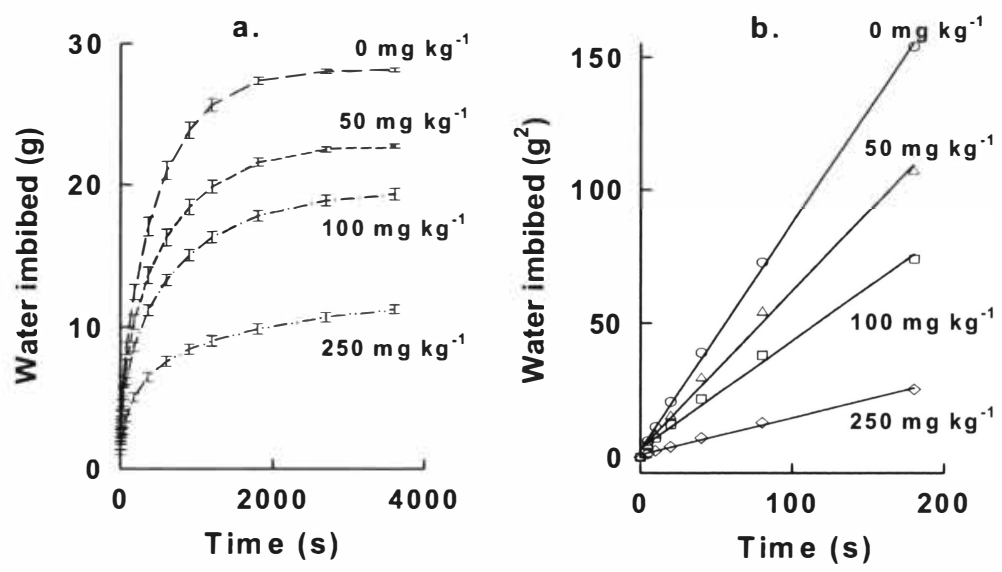

Figure 3. Capillary rise into sand moistened with artificial greywater and various concentations of oil and grease: a) grams water imbibed vs. time, ne 3; b) grams squared water imbibed vs. time. 
Capillary rise experiments were first run with clean, moist sand and ethanol as the imbibing solution. Using Equations 1 and 2, reand $c$ were determined to be $38 \mu \mathrm{m}$ and $8.6 \times 10^{-4} \mathrm{~cm}^{5}$, respectively. Subsequent imbibition experiments were run with columns containing $\mathrm{O} \& \mathrm{G}$ concentrations of 0 to $1,000 \mathrm{mg} / \mathrm{kg}$. Consistency in measurement of imbibition rates for replicate columns demonstrated uniformity of the method, as noted by error bars at selected data points on the graph (Figure $3 a$ ). It was observed that an O\&G concentration of $50 \mathrm{mg} / \mathrm{kg}$ caused an approximate $20 \%$ decrease in total imbibition. Imbibition decreased by about $60 \%$ at a concentration of $250 \mathrm{mg} / \mathrm{kg} \mathrm{O \& G}$ in the sand (Figure $3 a$ ). Above $250 \mathrm{mg} / \mathrm{kg} \mathrm{O \& G}$, no further decrease was observed (data not shown). Static contact angles calculated from the imbibition data ranged from $53^{\circ}$ for clean sand to $76^{\circ}$ for sand containing 250 to $1000 \mathrm{mg} / \mathrm{kg}$ or more O\&G (Table 2). Dynamic contact angles were calculated from the early (i.e., during first 200 seconds) linear, Washburn-type imbibition (Figure $3 b$ ). These contact angles were higher than the static contact angles and showed a smaller range, from $82^{\circ}$ for clean sand to $89^{\circ}$ for $250 \mathrm{mg} / \mathrm{kg}$ or more O\&G. The observed increase in both dynamic and static contact angle represents an approximately linear increase from 0 to $250 \mathrm{mg} / \mathrm{kg} \mathrm{O \& G}$. Beyond $250 \mathrm{mg} / \mathrm{kg} \mathrm{O \& G}$, there was no additional increase in contact angle. These results differ than published reports on the effect of surfactants from GW [11], in which each increase in surfactant concentration led to further depression of capillary rise, until imbibition was virtually prevented. The data suggest that $O \& G$ in soil of up to $1000 \mathrm{mg} / \mathrm{kg}$, while significantly affecting soil water movement, may not be able alone to render soil particles completely hydrophobic (i.e., contact angle $>90^{\circ}$ ). Furthermore, the data suggest that the specific mechanism causing water repellency expression is satisfied at around $250 \mathrm{mg} / \mathrm{kg}$ O\&G. One possible explanation is that at this threshold concentration, particle coatings are complete and changes to the particle surface energy are maximized. Additional O\&G may add thickness and durability to the coating (as indicated by the WDPT) but not cause further change to the contact angle. Further study is needed to explore this mechanism and the existence of threshold values for different soils and different $O \& G$ solutions.

Table 2. Water droplet penetration time (WDPT), static contact angle $\left(\theta_{\text {eq }}\right)$, and dynamic contact angle $\left(\theta_{d v}\right)$ for sand containing artificial greywater and various concentrations of oil and grease; $n \in 3$.

\begin{tabular}{cccc}
\hline $\begin{array}{c}\text { Oil \& grease } \\
(\mathrm{mg} / \mathrm{kg})\end{array}$ & WDPT & $\theta_{e q}$ & $\theta_{d y}$ \\
& seconds & & \\
\hline 0 & 0.0 & 52.8 & 82.2 \\
50 & 0.1 & 60.6 & 84.6 \\
100 & 0.2 & 66.0 & 86.3 \\
250 & 0.3 & 76.2 & 88.7 \\
500 & 0.8 & 75.6 & 89.0 \\
1000 & 2.1 & 75.1 & 88.7 \\
\hline
\end{tabular}




\section{CONCLUSIONS}

O\&G was found to be present in domestic $\mathrm{GW}$ at concentrations ranging from less than $10 \mathrm{mg} / \mathrm{L}$ for most household sources to around $200 \mathrm{mg} / \mathrm{L}$ for kitchen effluent. When this GW was used for long-term garden irrigation, $O \& G$ was observed to accumulate to a maximum depth of $20 \mathrm{~cm}$ in the soil profile. Higher concentrations $(200 \mathrm{mg} / \mathrm{kg})$ and a greater depth of accumulation were observed for the more oil-rich kitchen $G W$-irrigated soil than bath GW-irrigated soil $(150 \mathrm{mg} / \mathrm{kg})$. Nevertheless, both $\mathrm{GW}$-irrigated soils exhibited $O \& G$ concentrations in a range that laboratory studies suggest can significantly reduce water movement. Capillary rise experiments showed an approximate linear decrease in water imbibition when $O \& G$ concentrations were increased from 0 to $250 \mathrm{mg} / \mathrm{kg}$, with the maximum reduction of water imbibition approximately $60 \%$. Oil and grease concentrations greater than $250 \mathrm{mg} / \mathrm{kg}$ and up to $1000 \mathrm{mg} / \mathrm{kg}$ did not cause any further decrease in imbibition. The reason for this threshold is not known, but it is suggested that O\&G concentrations of $250 \mathrm{mg} / \mathrm{kg}$ maximized the potential changes to soil particle surface energy, as indicated by contact angle. Water droplet penetration time results showed no clear correlation between O\&G concentration and WDPT for field soils, possible due to the effects of other compounds. Laboratory prepared soils, on the other hand, showed a high correlation.

Laboratory tests indicated that O\&G concentrations similar to those observed in GWirrigated soils could increase the soil-water contact angle and significantly reduce water imbibition. This increase in soil water repellency could lead to water runoff and/or finger flow through the soil profile, both of which can exacerbate the migration of contaminants vertically or horizontally from the irrigated soil. Reduced water movement can also be detrimental to water availability for plant growth. While considering the use of GW for irrigation, the potential impact of $O \& G$ cannot be neglected.

\section{REFERENCES}

[1] Gross, A., Shmueli, O., Ronen, Z. and Raveh, E., 2007. Recycled vertical flow constructed wetland (RVFCW) - a novel method of recycling greywater for irrigation in small communities and households. Chemosphere, 66, 916-923.

[2] Friedler, E., 2004. Quality of individual domestic greywater streams and its implication for on-site treatment and reuse possibilities. Environmental Technology, 25, 997-1008.

[3] Tchobanoglous, G., Burton, F.L., Stensel, H.D., 2003. Wastewater Engineering: Treatment and Reuse, pp. 1819, McGraw-Hill, New York.

[4] Gray, S.R. and Becker, N.S.C., 2002. Contaminant flows in urban residential water systems. Urban Water, 4, 331-346.

[5] Bauters, T.W.J., Steenhuis, T.S., DiCarlo, D.A., Nieber, J.L., Dekker, L.W., Ritsema, C.J., Parlange, J.Y. and Haverkamp, R., 2000. Physics of water repellent soils. Journal of Hydrology 231-232, 233-243.

[6] Letey, J., Carrillo, M.L.K., Pang, X.P., 2000. Approaches to characterize the degree of water repellency. Journal of Hydrology, 231-232, 61-65.

[7] Doerr, S.H., Shakesby, R.A., Walsh, R.P.D., 2000. Soil water repellency: its causes, characteristics and hydro-geomorphological significance. Earth-Science Reviews, 51, 33-65. 
[8] Dekker, L.W. and Ritsema, C.J., 2000. Wetting patterns and moisture variability in water repellent Dutch soils. Journal of Hydrology, 231-232, 148-164.

[9] APHA, AWWA and WEF, 1998. Standard Methods for the Examination of Water and Wastewater, 20th ed., American Public Health Association, Washington.

[10] USEPA, 1999. Method 1664, Revision A: N-Hexane Extractable Material (HEM; Oil and Grease) and Silica Gel Treated N-Hexane Extractable Material (SGT-HEM; Non-polar Material) by Extraction and Gravimetry. United States Environmental Protection Agency, Office of Water.

[11] Wiel-Shafran, A., Ronen, Z., Weisbrod, N., Adar, E. and Gross, A., 2006. Potential changes in soil properties following irrigation with surfactant-rich greywater. Ecological Engineering 26, 348-354.

[12] Brown, R.C., 1947. The fundamental concepts concerning surface tension and capillarity. Proceedings of the Physical Society 59, 429-448.

[13] Siebold, A., Walliser, A., Nardin, M., Oppliger, M. and Schultz, J., 1997. Capillary Rise for Thermodynamic Characterization of Solid Particle Surface. Journal of Colloid and Interface Science 186, 60-70.

[14] Xue, H.T., Fang, Z.N., Yang, Y., Huang, J.P. and Zhou, L.W., 2006. Contact angle determined by spontaneous dynamic capillary rises with hydrostatic effects: Experiment and theory. Chemical Physics Letters 432, 326-330.

[15] Liu, Y. and German, R.M., 1996. Contact angle and solid-liquid-vapor equilibrium. Acta Materialia 44, 1657-1663.

[16] Christova-Boal, D., Eden, R.E. and McFarlane, S., 1996. An investigation into greywater reuse for urban residential properties. Desalination 106, 391-397.

[17] Plante, A.F. and Voroney, R.P., 1998. Decomposition of land applied oily food waste and associated changes in soil aggregate stability. J Environ Qual 27, 395 402.

[18] Cecutti, C., Agius, D., Caussade, B. and Gaset, A., 2002. Fate in the soil of ean oil additive of plant origin. Pest Management Science 58, 1236 - 1242. 